\title{
Interventions for people bereaved through suicide: systematic review
}

Catriona McDaid, Rebecca Trowman, Su Golder, Keith Hawton and Amanda Sowden

\section{Background}

Promoting the mental health of people bereaved through suicide is a key aim of the National Suicide Prevention Strategy.

\section{Aims \\ To evaluate the effects of interventions to support people bereaved through suicide.}

\section{Method}

We conducted a systematic review of data from controlled studies of interventions for people bereaved through suicide. Studies were identified using systematic searches, the methodological quality of included studies was assessed and narrative synthesis conducted.

\section{Results}

Eight studies were identified. None was UK-based and all but one study had substantial methodological limitations. When compared with no intervention, there was evidence of some benefit from single studies of a cognitive-behavioural family intervention of four sessions with a psychiatric nurse; a psychologist-led 10-week bereavement group intervention for children; and 8-week group therapy for adults delivered by a mental health professional and volunteer. The findings from studies comparing two or more active interventions were more equivocal.

\section{Conclusions}

Although there is evidence of some benefit from interventions for people bereaved by suicide, this is not robust. Further methodologically sound evidence is required to confirm whether interventions are helpful and, if so, for whom.

\section{Declaration of interest}

None. Funding detailed in Acknowledgements.
Suicide is a major public health issue. During 2002-2004 (latest available data) there were 8.6 suicide deaths per 100000 population in England, with the majority occurring in young adult males. ${ }^{1}$ The global mortality rate is estimated at 16 per 100000 - one death every 40 seconds. ${ }^{2}$ For every suicide it has been estimated that six people will experience intense grief, ${ }^{3}$ which extrapolates to around 35000 persons in the UK annually. Promoting the mental health of people bereaved through suicide is a key aim of the National Suicide Prevention Strategy. Although the effects of such a bereavement are not necessarily more severe than bereavement following other causes of death, there are certain aspects such as stigmatisation and a sense of rejection that may make coping particularly difficult. ${ }^{5}$ A distinction has been drawn between normal grief and complicated grief where there is persistent yearning for the deceased that is severe and disruptive to normal life. ${ }^{6}$ Such a response may be more common after deaths such as suicide. Diagnostic criteria have been proposed for inclusion in the American Psychiatric Association's Diagnostic and Statistical Manual of Mental Disorders: at least four of eight specific symptoms must be experienced frequently and/or be severely distressing for at least 6 months. ${ }^{7}$

Sources of support for those bereaved through suicide include general practitioners, specialised therapists, self-help groups, specialised reading material and internet sites. ${ }^{5}$ However, little is known about the effects of providing support. We conducted a systematic review with the purpose of evaluating the effects of interventions to assist people bereaved by suicide in dealing with the impact of the death and the consequences for their well-being.

\section{Method}

\section{Literature search}

Over 30 databases and other sources were searched up to 1 October 2007, including Medline, EMBASE, PsycINFO and the Science Citation Index, as well as sources of grey literature and ongoing studies. No language restriction was applied. Details of the search strategy and the databases searched are available from the authors. We checked reference lists of all the potentially relevant papers and contacted organisations and experts in the field. Two reviewers independently screened the search results for eligible studies. Disagreements were resolved by consensus or through consultation with a third reviewer.

\section{Inclusion criteria}

Any type of intervention targeted at adults or children bereaved through suicide was eligible for inclusion, for example support groups, self-help and volunteer-led groups, as well as therapeutic interventions delivered by health professionals. There was no restriction on the relationship to the person who had died: studies of people bereaved through a personal or professional relationship were also eligible. All outcomes (qualitative and quantitative) were considered relevant. The key restriction was that only randomised controlled trials (RCTs) and studies with a control or comparison group (including cohort studies) were eligible. This was viewed as particularly important owing to the changing nature of grief over time. $^{3}$

\section{Data extraction and quality assessment}

Key study characteristics and outcomes were extracted and studies were quality-assessed by one reviewer and checked for accuracy by a second. Disagreements were resolved through consensus, and if necessary a third reviewer was consulted. One French-language paper required translation. The quality criteria (see Appendix) were based on the Centre for Reviews and Dissemination's guidance for undertaking systematic reviews, ${ }^{8}$ and a report on evaluating non-randomised studies. ${ }^{9}$ In order to assess the integrity of the intervention we drew on the Quality Assessment Tool for Quantitative Studies. ${ }^{10}$ 


\section{Data synthesis}

Given the diversity of the studies in terms of settings, interventions, outcomes and outcome measures used, we undertook a narrative synthesis based on recent guidance. ${ }^{11,12}$ The primary study findings were interpreted, and similarities and differences between the studies investigated. This included consideration of study design, methodological quality, whether the study was appropriately powered, intervention characteristics and delivery, participants and outcome measures. Studies were grouped according to whether they had an active comparison group.

\section{Results}

\section{Study characteristics}

Eight studies met the inclusion criteria (Fig. 1). ${ }^{13-20}$ There were four RCTs, ${ }^{15-17,20}$ one controlled study ${ }^{18}$ and three observational studies with a control group, ${ }^{13,14,19}$ one of which was retrospective $^{14}$ (online Table DS1). No UK-based study was identified. In the majority of studies the participants were members of the dead person's family, although two studies focused on school or university students. There were four studies of adults only, ${ }^{15,16,19,20}$ and one of children only. ${ }^{13}$ Two included a small number of children in their comparison group, ${ }^{14,18}$ and in one, outcome was reported separately for adults and children. ${ }^{17}$ In most studies the majority of participants were women. Where ethnic data were reported, participants were predominantly White. ${ }^{14-17}$ Data on other participant-related potential prognostic factors were not reported consistently across the studies. Baseline scores on some key scales (where available) are reported in online Table DS1 and data from other measures used are available from the authors. Participants were recruited by researchers, ${ }^{16,17,20}$ professional referral, ${ }^{13,14}$ and multiple sources such as self-referral and professional referral. ${ }^{15,18,19}$

The studies had few inclusion or exclusion criteria (online Table DS1) and none of the studies selected participants on the basis of vulnerability to mental health problems such as depression or complicated grief. None of the included studies investigated interventions targeted at professionals such as emergency services personnel or health professionals. Although

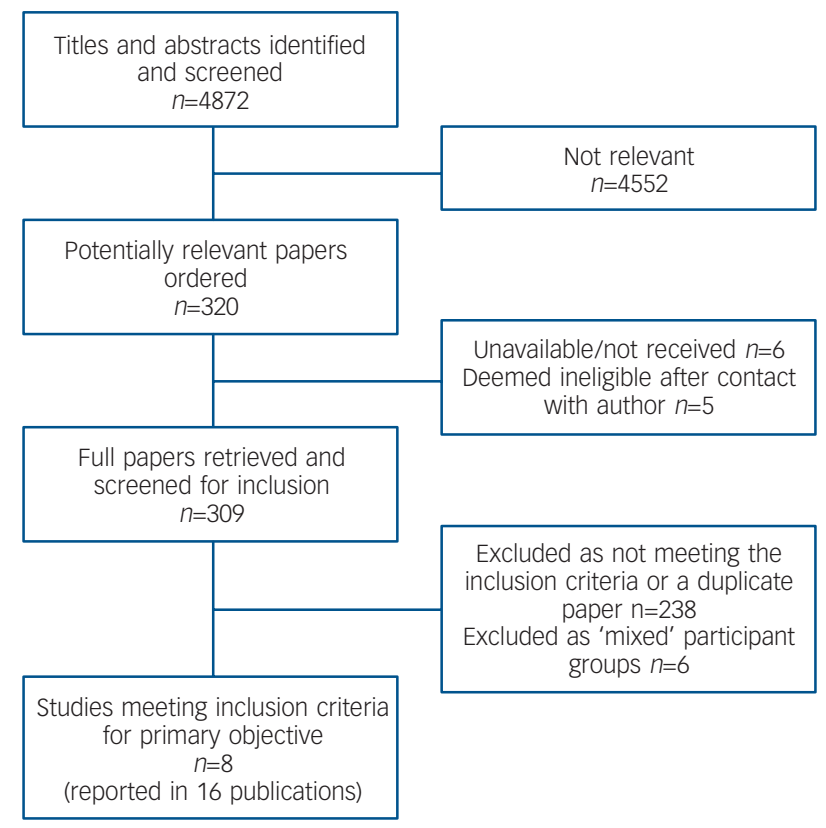

Fig. 1 Study selection. most studies used standardised outcome measures, there was little consistency in the measures chosen: three used the Beck Depression Inventory (BDI) and two the Impact of Event Scale (IES). Owing to the diversity of assessment instruments, it was difficult to assess the baseline similarity of participants across studies. Apart from three studies, ${ }^{15,19,20}$ the length of follow-up was less than 1 year. It is unlikely, therefore, that participants were followed long enough to allow a meaningful assessment of outcome in most studies.

The settings in which the interventions occurred were also diverse and included a school, ${ }^{13}$ the family home, ${ }^{20}$ the scene of the suicide, ${ }^{14}$ a laboratory at a university, ${ }^{16}$ and a suicide prevention centre. ${ }^{18,19}$ Two studies did not report any details about the setting. ${ }^{15,17}$ With the exception of one study, ${ }^{16}$ the interventions were delivered in a family or group context by mental health professionals ${ }^{15,17,19,20}$ or by mental health professionals in conjunction with volunteers who had themselves been bereaved by suicide. ${ }^{14,18}$

\section{Quality}

With the exception of the study by de Groot et al, ${ }^{20}$ substantial methodological problems were identified in the studies. The key threats to study validity are summarised in Table 1; the full quality appraisal is available from the authors.

Two of the RCTs were truly random, ${ }^{15,20}$ one was not (participants were assigned in alternating order), ${ }^{17}$ and one did not report how randomisation was carried out. ${ }^{16}$ One RCT attempted to conceal treatment allocation. ${ }^{20}$ There is therefore the risk that the effectiveness of the interventions was overestimated in the other studies, especially given that subjective outcome measures were used. The remaining studies used various methods to assign participants to the intervention and comparison groups, all of which had a high risk of selection bias. There were differences between groups at baseline in three studies, ${ }^{16-18}$ or it was unclear whether they were similar. ${ }^{13,15}$ None of the studies appeared to conduct a full intention-to-treat analysis including all allocated participants. In some situations this can lead to an overestimation of the treatment effect, but it is worth noting that in the study by de Groot et al those who dropped out had slightly more favourable scores at baseline for depression, complicated grief and selfblame. $^{20}$

The studies were generally small and, with the exception of the de Groot et al study, ${ }^{20}$ it was unclear whether they were appropriately powered to detect an effect on all the outcomes measured. Four of the studies indicated (explicitly or implicitly) that the intervention was implemented based on a treatment protocol or manual. ${ }^{15-17,20}$ It was possible to assess the fidelity of the intervention in only one study, which measured consistency of delivery. ${ }^{17}$ Hence, there is the question of whether the intervention and comparison were delivered as planned, and in a consistent manner.

\section{Study findings}

\section{Intervention $v$. no intervention}

There was some evidence of a positive effect of interventions when compared with no intervention (Table 1). A 10-week bereavement group intervention for children, led by psychologists, was more effective than no intervention at reducing anxiety and depression, but not social adjustment and post-traumatic stress. ${ }^{17}$ This was a small study and it was unclear whether it was appropriately powered to detect an effect on the outcomes measured. In addition, a fifth of the comparison group sought other interventions, which might have diluted or inflated the effect of the intervention. 


\begin{tabular}{|c|c|c|c|}
\hline Study & Outcome measures used & Summary of results & Main threats to validity \\
\hline $\begin{array}{l}\text { Campbell } \\
(2002)^{14}\end{array}$ & $\begin{array}{l}\text { Length of time between intervention } \\
\text { and seeking treatment }\end{array}$ & $\begin{array}{l}\text { The intervention group sought treatment significantly } \\
\text { quicker than the comparison group. Intervention, mean } \\
37.7 \text { days (s.d.=1.2); comparison, } 222.2 \text { days (s.d.=240.7), } \\
P<0.001\end{array}$ & $\begin{array}{l}\text { Non-randomised study using partly } \\
\text { historical controls } \\
\text { Generalisability } \\
\text { Inadequate outcome measure - based on } \\
\text { the assumption that seeking help following } \\
\text { the intervention is a positive outcome }\end{array}$ \\
\hline $\begin{array}{l}\text { De Groot } \\
\text { et al } \\
(2007)^{20}\end{array}$ & $\begin{array}{l}\text { Primary outcome: self-reported } \\
\text { complicated grief measured with ITG } \\
\text { Secondary outcomes: } \\
\text { CESD } \\
\text { Suicidal ideation } \\
\text { Perception of being to blame for } \\
\text { the suicide (Likert scale) } \\
\text { TRGR2L }\end{array}$ & $\begin{array}{l}\text { There was no statistically significant difference between } \\
\text { intervention and control groups on the primary outcome } \\
\text { (ITG: adjusted mean difference }-0.61,95 \% \mathrm{Cl}-6.05 \text { to } \\
4.83, P=0.82 \text { ) } \\
\text { There was a statistically significant benefit for the } \\
\text { intervention group compared with control in perception } \\
\text { of being to blame (adjusted OR=0.18, } 95 \% \mathrm{Cl} 0.05 \text { to } 0.67 \text {, } \\
P=0.01 \text { ) but not for suicidal ideation (adjusted } \mathrm{OR}=1.08 \text {, } \\
95 \% \mathrm{Cl} 0.33 \text { to } 3.57, P=0.89 \text { ), CESD (adjusted mean } \\
\text { difference } 1.97,95 \% \mathrm{Cl}-1.65 \text { to } 5.60, P=0.28 \text { ) or TRGR2L } \\
\text { (adjusted OR=0.39, } 95 \% \mathrm{Cl} 0.15 \text { to } 1.01, P=0.06 \text { ) } \\
\text { When unadjusted scores were used there was no } \\
\text { significant difference between groups on any of the } \\
\text { measures. All analyses were adjusted for clustering of } \\
\text { symptoms within families. The adjusted scores accounted } \\
\text { for gender, having lived with the person who had died, } \\
\text { and closeness of the relationship. In addition, the analyses } \\
\text { of suicidal ideation and perception of being to blame were } \\
\text { adjusted for baseline depression }\end{array}$ & $\begin{array}{l}\text { No substantial threats to validity } \\
\text { The study was randomised and although } \\
\text { the method of allocation concealment was } \\
\text { not ideal (a list was used) the authors state } \\
\text { that an independent secretary administered } \\
\text { the procedure. There were differences } \\
\text { between the groups at baseline but an } \\
\text { adjusted analysis was conducted to } \\
\text { account for these differences. A greater } \\
\text { proportion of the intervention group were } \\
\text { male and had lived with the deceased } \\
\text { compared with the control group }\end{array}$ \\
\hline $\begin{array}{l}\text { Farberow } \\
(1992)^{18}\end{array}$ & $\begin{array}{l}\text { Intensity of nine emotions (anger } \\
\text { towards deceased, anger towards } \\
\text { self, anxiety, depression, grief, guilt, } \\
\text { puzzlement, shame, suicidal ideation), } \\
\text { rated as high, moderate or low }\end{array}$ & $\begin{array}{l}\text { There was improvement on eight emotions (anger } \\
\text { towards deceased, anger towards self, anxiety, } \\
\text { depression, grief, guilt, puzzlement, shame) for the } \\
\text { intervention group compared with one for the } \\
\text { comparison group at } 8 \text { weeks. Statistical analysis was } \\
\text { not conducted and comments on improvement seemed } \\
\text { to be based on change within groups over time, not } \\
\text { between groups }\end{array}$ & $\begin{array}{l}\text { Non-randomised study with high risk of } \\
\text { selection bias. There were differences } \\
\text { between the groups at baseline }\end{array}$ \\
\hline $\begin{array}{l}\text { Pfeffer } \\
\text { et al } \\
(2002)^{17}\end{array}$ & $\begin{array}{l}\text { Beck Depression Inventory (parents) } \\
\text { Childhood Post-traumatic Stress } \\
\text { Reaction Index } \\
\text { Children's Depression Inventory } \\
\text { Revised Children's Manifest Anxiety } \\
\text { Scale } \\
\text { Social Adjustment Inventory for } \\
\text { Children and Adolescents }\end{array}$ & $\begin{array}{l}\text { There was a greater reduction in anxiety (RCMAS) and } \\
\text { depression (CDI) at } 12 \text { weeks for children who received } \\
\text { the intervention compared with those who did not } \\
\text { (statistically significant), but not for social adjustment } \\
\text { (SAICA), post-traumatic stress (CPSRI) or parental } \\
\text { depression (BDI) } \\
\text { Mean RCMAS score from baseline to follow-up: } \\
\text { intervention } 49.3 \text { (s.d.=9.9) to } 39.6 \text { (s.d.=10.6); } \\
\text { comparison } 52.6 \text { (s.d.=6.5) to } 56.5 \text { (s.d.=10.2), } P \leqslant 0.001 \\
\text { Mean CDI score from baseline to follow-up: intervention } \\
46.5 \text { (s.d.=8.7) to } 44.1 \text { (s.d.=8.7); comparison } 53.7 \\
\text { (s.d.=11.8) to } 53.9 \text { (s.d.=7.8), } P \leqslant 0.006\end{array}$ & $\begin{array}{l}\text { Inadequate method of randomisation to } \\
\text { groups leading to risk of selection bias. } \\
\text { There were differences between the } \\
\text { groups at baseline } \\
\text { Extremely high loss to follow-up in the } \\
\text { control group }\end{array}$ \\
\hline
\end{tabular}

There were also differences between the groups at baseline: children in the intervention group were younger, had better social adjustment and the length of time since bereavement was shorter.

An 8-week group therapy intervention delivered by a mental health professional and a volunteer was associated with a lessening in intensity of eight of nine emotions assessed compared with one of nine emotions for the control group. ${ }^{18}$ However, a statistical analysis was not reported for differences between groups, and at baseline the intervention group reported greater feelings of grief, shame and guilt than the comparison group. The reliability and validity of the outcome measure were unclear. The time lapse between bereavement and attending a crisis centre for assessment and treatment was shorter in those who had received an active outreach intervention at the scene of the suicide compared with those who had not; ${ }^{14}$ however, this outcome measure is based on the assumption that seeking help following the intervention is a positive outcome. In the absence of any information about individuals who received the outreach intervention but did not seek help at the crisis centre, it is unclear whether this was an appropriate assumption.
The third study was a cluster randomised trial of family-based cognitive-behavioural therapy (CBT), compared with usual care, for first-degree relatives and spouses. ${ }^{20}$ The intervention consisted of four sessions of CBT with a trained psychiatric nurse counsellor, 3-6 months following the bereavement. This was the best-quality study found: there was an adequate method of randomisation, an appropriate method was used to adjust for baseline differences and loss to follow-up was low. Thirteen months after the bereavement there was no beneficial effect on the primary outcome of self-reported complicated grief reaction (measured by the Inventory for Traumatic Grief) or on suicidal ideation or depression in the intervention group compared with controls. There was evidence, however, of fewer maladaptive grief reactions and less perception of being to blame for the suicide. ${ }^{20}$

\section{Studies using an active comparator}

The findings from the studies comparing two or more active interventions were equivocal (Table 2). Among undergraduates, writing therapy over a 2 -week period which involved describing 


\begin{tabular}{|c|c|c|c|}
\hline Study & Outcome measures used & Summary of results & Main threats to validity \\
\hline $\begin{array}{l}\text { Constantino } \\
\text { et al } \\
(2001)^{15}\end{array}$ & $\begin{array}{l}\text { Beck Depression Inventory } \\
\text { Brief Symptom Inventory } \\
\text { Grief Experience Inventory } \\
\text { Social Adjustment Scale }\end{array}$ & $\begin{array}{l}\text { There was no statistically significant difference between } \\
\text { groups up to } 12 \text { months follow-up on any of the } \\
\text { assessment scales (BDI, BSI, GEI, SAS) }\end{array}$ & $\begin{array}{l}\text { This was a randomised study but the data } \\
\text { for between-group comparisons were not } \\
\text { reported. The authors stated there was no } \\
\text { between-group difference, and combined } \\
\text { the two groups to make before-and-after } \\
\text { comparisons. Owing to the lack of a } \\
\text { no-intervention control group it is unclear } \\
\text { whether the improvement in the two } \\
\text { groups would have occurred anyway }\end{array}$ \\
\hline $\begin{array}{l}\text { Kovac \& } \\
\text { Range } \\
(2000)^{16}\end{array}$ & $\begin{array}{l}\text { Grief Experience Questionnaire } \\
\text { Grief Recovery Questionnaire } \\
\text { Impact of Event Scale } \\
\text { Non-routine healthcare visits } \\
\text { (self-reported) }\end{array}$ & $\begin{array}{l}\text { There was a significant improvement in grief associated } \\
\text { with suicide (GEQ) for the intervention group compared } \\
\text { with the control group (statistically significant) at } 8 \text { weeks } \\
\text { but not on any of the other measures used (GRQ, IES, } \\
\text { non-routine healthcare visits) } \\
\text { Mean GEQ total score from baseline to } 8 \text { weeks: } \\
\text { intervention } 109.9 \text { (s.d.=37.2) to } 90.3 \text { (s.d.=25.6); } \\
\text { comparison } 122.6 \text { (s.d.=29.0) to } 106.1 \text { (s.d.=27.5), } \\
P<0.001\end{array}$ & $\begin{array}{l}\text { Randomised study, but it was not possible } \\
\text { to assess adequacy of randomisation and } \\
\text { allocation concealment. There were } \\
\text { differences between the groups at baseline } \\
\text { Generalisability } \\
\text { Conducted with undergraduates who were } \\
\text { rewarded with course credits for } \\
\text { participation }\end{array}$ \\
\hline $\begin{array}{l}\text { Poijula } \\
\text { et al } \\
(2001)^{13}\end{array}$ & $\begin{array}{l}\text { Hogan Sibling Inventory of } \\
\text { Bereavement } \\
\text { Impact of Event Scale }\end{array}$ & $\begin{array}{l}\text { Significantly more of the pupils in school A were classified } \\
\text { as having high-intensity grief compared with the other } \\
\text { schools (HSIB: school A } 25 \% \text { in high-intensity grief group } \\
\text { compared with } 5 \% \text { in school B and } 0 \% \text { in school C), 4-9 } \\
\text { months following the intervention. When a comparison } \\
\text { was made between those who received an intervention } \\
\text { and those who did not, there was no between-group } \\
\text { difference in the proportion of participants classified as } \\
\text { being at high and low risk of intense grief. Based on IES, } \\
\text { the proportion of participants defined as being at high } \\
\text { risk of PTSD were } 24.1 \% \text { for school A, 25\% for school B } \\
\text { and } 15.4 \% \text { for school C (NS) }\end{array}$ & $\begin{array}{l}\text { Observational study using indistinct com- } \\
\text { parators. High risk of confounding }\end{array}$ \\
\hline $\begin{array}{l}\text { Seguin } \\
\text { et al } \\
(2004)^{19}\end{array}$ & $\begin{array}{l}\text { Beck Depression Inventory } \\
\text { Tessier Scale of Grief }\end{array}$ & $\begin{array}{l}\text { There was improvement in depression scores (BDI) in the } \\
\text { four groups over } 1 \text { year though it was unclear whether } \\
\text { there was any between-group difference (statistical } \\
\text { analysis not conducted). Mean BDI scores from baseline } \\
\text { to } 12 \text { months follow-up: group A } 15.0 \text { (s.d.=9.37) to } \\
11.6 \text { (s.d.=11.6); group B } 20.5 \text { (s.d.=9.6) to } 8.7 \text { (s.d.=7.0); } \\
\text { group C } 17.7 \text { (s.d.=11.4) to } 0 \text { (data available for only one } \\
\text { participant); group D } 21 \text { (s.d.=9.4) to } 13.6 \text { (s.d.=12.0). } \\
\text { The authors state that scores on the TSG remained } \\
\text { stable, although this is not clear from the tables reported }\end{array}$ & $\begin{array}{l}\text { Observational study using indistinct } \\
\text { comparators. The complexity of these } \\
\text { interventions is such that one cannot be } \\
\text { sure that the only difference is treatment } \\
\text { duration. High risk of confounding }\end{array}$ \\
\hline
\end{tabular}

BDI, Beck Depression Inventory; BSI, Brief Symptom Inventory; CDI, Children's Depression Inventory; CESD, Center for Epidemiologic Studies Depression scale, CPSRI, Childhood Posttraumatic Stress Reaction Index; GEI, Grief Experience Inventory; GEQ, Grief Experience Questionnaire; GRQ, Grief Recovery Questionnaire; HSIB, Hogan Sibling Inventory of Bereavement; IES, Impact of Event Scale; ITG, Impact of Traumatic Grief; NS, not significant; PTSD, post-traumatic stress disorder; RCMAS, Revised Children's Manifest Anxiety Scale; SAICA, Social Adjustment Inventory for Children and Adolescents; SAS, Social Adjustment Scale; TRGR2L, Traumatic Grief Evaluation of Response to Loss; TSG, Tessier Scale of Grief.

the events and emotions around their loss had some marginal benefits compared with a trivial writing condition. ${ }^{16}$ However, participants in the profound writing group also had less severe grief than the comparison group at baseline. In a school setting, implementation of a crisis intervention involving first talk through and psychological debriefing was associated with fewer pupils experiencing high-intensity grief, but not stress response, than a less intense crisis intervention. ${ }^{13}$ A study comparing four professionally led, closed-group interventions of 2 months, 4 months, 6 months and 12 months duration reported a trend in all four groups towards decreasing depression over the 12-month follow-up period. ${ }^{19}$ There was some variation between groups in the decrease in BDI score (least reduction in the 2-month group and greatest in the 4-month group), although there was considerable and unequal loss to follow-up across groups, and what appeared to be baseline differences between the groups. In both these studies there was a high risk of confounding due to indistinct comparators. ${ }^{13,19}$ There was no benefit in participating in a health professional-led bereavement group compared with a social group intervention for women bereaved by the suicide of their spouse, although it was unclear whether this study was appropriately powered to detect an effect. ${ }^{13}$

\section{Discussion}

Despite extensive searches, no language restrictions and broad inclusion criteria we identified only eight eligible studies, none of which focused on health professionals.

\section{Interpretation of results}

Six of the eight studies showed some evidence of benefit for participants receiving the intervention on at least one measure. However, because of the differences between studies and the methodological limitations, considerable care needs to be taken before accepting the assumption that some kind of intervention is better than none. Some of the methodological limitations, such as small sample size or the control group receiving support from elsewhere, might have resulted in the treatment effect being underestimated. However, the latter might also have led to an 
overestimation of the treatment effect if the additional support was detrimental to the control group. Other limitations such as non-randomised allocation of participants to intervention groups might also have led to an overestimation. Despite positive findings from the study with the lowest risk of bias, uncertainty remains, as there was no evidence of benefit on the primary outcome of selfreported complicated grief. This early-stage intervention has the benefit of being brief, although replication and evidence of a stronger treatment effect would increase confidence in the effectiveness of such an intervention. ${ }^{20}$

Owing to the paucity of data it was not possible to explore whether the effects of interventions varied with age, gender, selfreferral, characteristics of the deceased or the nature of the relationship between the bereaved and the deceased. Whether bereaved individuals benefit from an intervention may depend on whether or not they are experiencing complicated grief., ${ }^{6,21}$ However, it was not possible to explore this issue owing to the limited data available.

The review is limited by the small number of studies available, their diversity and general poor quality. This reflects the findings of a systematic review of bereavement care interventions for general population groups, where the authors reported considerable theoretical and clinical diversity, inadequate reporting of intervention procedures, methodological flaws, and few replication studies. ${ }^{22}$ The evidence for a positive effect of interventions for general bereaved populations is also weak. ${ }^{22-24}$ Our review did not address the question of whether interventions for people bereaved through suicide need to be different from those provided to people bereaved through other means. Given the limitations of the studies of general bereaved populations and populations bereaved through suicide, it is unlikely that data are currently available to address this question. However, it is an important issue that should be addressed.

\section{Implications for practice and research}

The evidence we have identified and appraised is not robust; clear implications for practice therefore cannot be drawn. However, based on the limited evidence available from single studies, the following tentative suggestions are made: psychologist-led group therapy for children may reduce anxiety and depression, ${ }^{17}$ and combined health professional- and volunteer-led group therapy for adults may reduce feelings of anger towards the deceased and self, anxiety, depression, grief, guilt, puzzlement and shame. ${ }^{18}$ There is also recent evidence that a brief CBT family intervention by a trained psychiatric nurse counsellor resulted in fewer maladaptive grief reactions and less self-blame. ${ }^{20}$ However, it remains unclear whether interventions are helpful and, if they are, the best timing of such intervention. Similarly, it is unclear whether they are helpful for all people bereaved through suicide or whether there are specific individuals who might benefit most - for example those experiencing complicated grief.

The views of participants were noticeably absent from the studies. Their views on the interventions received were generally not obtained and it was unclear whether the support given was viewed as helpful and appropriate to their needs. Obtaining the views of participants in future studies is vital to help identify the effective components of interventions and to establish what support is helpful to people bereaved by suicide. Grief can be culture-specific: consideration needs to be given to the generalisability of evidence to different ethnic groups. Research is required on the effectiveness of interventions in different ethnic groups as well as the potentially different responses of males and females, people of different ages and background as well as those experiencing complicated grief.
There is a pressing need for methodologically sound RCTs. Although this is a challenging study design to implement in this field, the recently published trial of CBT illustrates that it is possible. Sample size calculations need to take into account the need for analysis to investigate the impact of potentially important prognostic factors on outcome. It would aid meaningful comparison between studies if a core set of outcome measures could be used: consideration needs to be given to whether to use generic scales for anxiety and depression and/or grief specific measures.

Catriona McDaid, PhD, Rebecca Trowman, MSC, Su Golder, MSC, Centre for Reviews and Dissemination, University of York, York; Keith Hawton, DSC, DM, FRCPsych, Centre for Suicide Research, University Department of Psychiatry, Warneford Hospital, Oxford; Amanda Sowden, PhD, Centre for Reviews and Dissemination, University of York, York, UK

Correspondence: Dr Catriona MCDaid, Centre for Reviews and Dissemination, University of York, York Y010 5DD, UK. Email: cm36@york.ac.uk

First received 25 Apr 2007, final revision 18 Mar 2008, accepted 10 Apr 2008

\section{Acknowledgements}

This study was funded by the Policy Research programme of the Department of Health The views expressed in the publication are those of the authors and not necessarily those of the Department of Health.

\section{Appendix}

\section{Quality assessment criteria}

If the study was described as a randomised controlled trial (RCT), was the assignment to treatment groups really random?

If it was described as an RCT, was the treatment allocation concealed? Was the assignment of participants to treatments described? Were the groups balanced at baseline in relation to potential confounders?

Were baseline differences adequately adjusted for in the design or in the analysis?

Were important confounders reported?

Was outcome assessment made masked to group allocation?

What proportion of participants completed the study?

Were withdrawal rates and reasons similar across intervention and control groups?

Were the data collection tools shown or known to be valid for the outcome?

Were the data collection tools shown or known to be reliable for the outcome?

Was the statistical analysis appropriate?

Did the analyses include an intention-to-treat analysis?

Was the consistency of the intervention measured?

If yes, was the intervention provided to all participants in the same way?

Is it likely that participants received an unintended co-intervention?

Is it likely that contamination might have influenced the results?

Was the length of follow-up long enough for the outcomes to occur?

\section{References}

1 National Institute for Mental Health in England. National Suicide Prevention Strategy for England: Annual Report on Progress 2005. UK Department of Health, 2006.

2 World Health Organization. Mental Health: Suicide Prevention (SUPRE). WHO, 2006.

3 Clark SE, Goldney RD. The impact of suicide on relatives and friends. In International Handbook of Suicide and Attempted Suicide (eds K Hawton, $\mathrm{K}$ van Heeringen): 467-84. Wiley, 2000.

4 Department of Health. National Suicide Prevention Strategy for England. Department of Health, 2002.

5 Hawton K, Simkin S. Helping people bereaved by suicide: their needs may require special attention. Bereavement Care 2003; 22: 41-2. 
6 Hawton K. Complicated grief after bereavement: psychological interventions may be effective. BMJ 2007; 334: 962-3.

7 Zhang B, El-Jawahri A, Prigerson H. Update on bereavement research: evidence-based guidelines for the diagnosis and treatment of complicated bereavement. J Palliat Med 2006; 9: 1188-203.

8 NHS Centre for Reviews and Dissemination. Undertaking Systematic Reviews of Research on Effectiveness: CRD Guidelines For Those Carrying Out or Commissioning Reviews. CRD Report 4, 2nd edn. CRD, 2001.

9 Deeks JJ, Dinnes J, D’Amico R, Sowden AJ, Sakarovitch C, Song F, Petticrew M, Altman DJ. Evaluating non-randomised intervention studies. Health Technol Assess 2003; 7: 1-186.

10 Hamilton Effective Public Health Practice Project Team. Dictionary for the Effective Public Health Practice Project Quality Assessment Tool for Quantitative Studies. Hamilton Effective Public Health Practice Project, 2003.

11 Arai L, Britten N, Popay J, Roberts H, Petticrew M, Rodgers M, Sowden A. Testing methodological developments in the conduct of narrative synthesis: a demonstration review of research on the implementation of smoke alarm interventions. Evidence Policy 2007; 3: 361-83.

12 Popay J, Roberts H, Sowden A, Petticrew M, Britten N, Arai L, Roen K, Rodgers $\mathrm{M}$. Developing guidance on the conduct of narrative synthesis in systematic reviews. J Epidemiol Community Health 2005; 59(suppl 1): A7.

13 Poijula S, Dyregrov A, Wahlberg KE, Jokelainen J. Reactions to adolescent suicide and crisis intervention in three secondary schools. Int J Emerg Ment Health 2001; 3: 97-106.

14 Campbell FR. The influence of an active postvention on the length of time elapsed before survivors of suicide seek treatment. Diss Abs Int A Hum Soc Sci 2002; 63: 753 .
15 Constantino RE, Sekula LK, Rubinstein EN. Group intervention for widowed survivors of suicide. Suicide Life Threat Behav 2001; 31: 428-41.

16 Kovac SH, Range LM. Writing projects: lessening undergraduates' unique suicidal bereavement. Suicide Life Threat Behav 2000; 30: 50-60.

17 Pfeffer CR, Jiang H, Kakuma T, Hwang J, Metsch M. Group intervention for children bereaved by the suicide of a relative. J Am Acad Child Adolesc Psychiatry 2002; 41: 505-13.

18 Farberow NL. The Los Angeles Survivors-After-Suicide program. An evaluation. Crisis 1992; 13: 23-34.

19 Seguin M, Vinet-Bonin A, Senecal I. Evaluation de programmes de postvention [Evaluation of four suicide bereavement programs]. Rev Fr Psychiat Psychol Med 2004; 8: 17-24.

20 De Groot M, de Keijser J, Neeleman J, Kerkhof A, Nolen W, Burger H. Cognitive behaviour therapy to prevent complicated grief among relatives and spouses bereaved by suicide: cluster randomised controlled trial. BMJ 2007; 334: 994.

21 Stroebe W, Schut $H$, Stroebe MS. Grief work, disclosure and counseling: do they help the bereaved? Clin Psychol Rev 2005; 25: 395-414.

22 Forte AL, Hill M, Pazder R, Feudtner C. Bereavement care interventions: a systematic review. BMC Palliat Care 2004; 3: 3.

23 Kato PM, Mann T. A synthesis of psychological interventions for the bereaved. Clin Psychol Rev 1999; 19: 275-96.

24 Litterer Allumbaugh D, Hoyt WT. Effectiveness of grief therapy: a metaanalysis. J Couns Psychol 1999; 46: 370-80. 